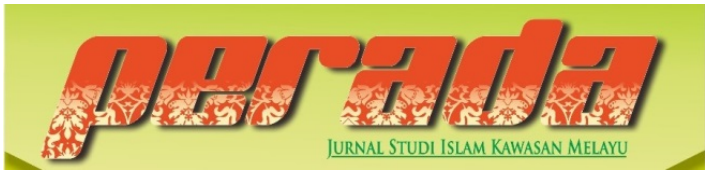

Perada: Jurnal Studi Islam Kawasan Melayu
P-ISSN 2656-7202 E-ISSN 2655-6626

Volume 2 Nomor 2, Juni-Desember 2019

DOI: $10.35961 /$ perada.v2i2.84

\title{
أهمية دراسة اللغة العربية في فهم معاني القرآن (دراسة عن الفعل العربي)
}

\section{Aidillah Suja}

STAIN Sultan Abdurrahman Kepulauan Riau

adillah@stainkepri.ac.id

\section{ملخص}

الدراسة عن اللغة العربية هي دراسة جذّابة على دراستها، هذه اللغة ليست لغة اتصالية فحسب، بل إها لغة الهية لأن مصدران في الإسلام وهما القرآن والحديث تكتبا باللغة العربية. ولمعرفة القرآن والحديث معرفة تامّة وجب علينا فهم قواعد اللغة العربية منها "الفعل" و "الاسم" و "الحرف". بفهم تلك القواعد تسهّلنا على معرفة معاني القرآن والحديث معرفة تامّة. في هذا البحث قد بحث الباحث أحد من دراسة اللغة العربية وهي عن "الفعل" في القرآن الكريم. موضوع البحث هو "الفعل"، أمّا نوع البحث هو البحث المكتبي، طريقة جمع البيانات هي المراقبة وبقراءة الكتب المتعلقة بالبحث، وطريقة تحليل البيانات هي طريقة تحليل المضمون وهي بتحليل الكتب المتعلقة والآيات القرآنية المتعلقة بالبحث. النتيجة من هذا البحث هي أنّ دراسة اللغة العربية "الفعل" لها دور عظيم في فهم القرآن الكريم وهذه الدراسة تسهّل المسلمين على معرفة معاني القرآن معرفة تامة. فمن الدراسة التي قام بها الباحث من قبل كثير من الطلاب الجامعي أخطأ في فهم آية القرآن خصوصا ما يتعلق بأسلوب الذي فيه "الفعل"، ولكن بعد أن يتعلموا اللغة العربية عن "الفعل" خصوصا فيقدر على فهم بعض آية القرآن فهما جيدا. فبمؤسس على ما سبق ذكره أخذ الباحث الاستنباط أن الدراسة عن اللغة العربية واجبة على كل مسلم ومسلمة، خصوصا للطلاب الجامعي باعتبار أهبّم الأجيل المستقبلة.

$$
\text { الكلمة الرئيسية: الدراسة، العربية، الفعل، القرآن. }
$$




\section{ABSTRACT}

Learning about study of arabic language is very interesting to learnd, it is not only about complex comunication language but also devine revelation language for Muslim where two of refrences of islamic syari'ah is Al-qur'an and Hadist writed with arabic language. In addition to understand the Al-qur'an and Hadist must cognize several structure, grammatical of arabic language such as "verb" in arabic langguage, "isim" and "Harfun". To understanding gramatical of arabic language or basic of arabic langguage inderectly a reader easier to understand Ilahi Verces. In this study, "verb" as one of Arabic language learning in Al-Qur'an was investigated by the researcher. The objects of study were "verb". The research design used was literature study. The data were collected by observation and collecting the references related to the study and then were analyzed by using content analysis of the Ayahs of Al-Qur'an related to the study. The result showed that the Arabic language learning about "verb" has a great role which helps Muslim to comprehend the meaning of Ayahs of Al-Qur'an verb well. Then, it was also found that there were many students that were still misunderstanding in comprehending AlQur'an, specifically the parts containing "verb". After they learn it, they were able to comprehend those Ayahs well. Therefore, it can be concluded that learning Arabic language is a compulsory for Muslim, especially for student because they are future generation.

Keyword: learning, Arabic, verb, Al-Qur'an.

$$
\begin{aligned}
& \text { والقوافى، وقرض الشعر، و والإنشاء، والخطابة، تمهيد } \\
& \text { اللّغة هي ألفاظ يعبّر بها كلّ قوم عن } \\
& \text { مقاصدهم. اللّغة العربية هي الكلمات التّي يعبّر } \\
& \text { كها العرب عن أغراضهم. إذّا قد وصلت إلينا من } \\
& \text { طريق النقل. و وحفظها لنا القرآن العزيز } \\
& \text { والأحاديث الشّريفة وما رواه الثّقات من منثور } \\
& \text { العرب ومنظومها. } 1 \text { وهذان مصدرا تعاليم الإسلام ومات روه } \\
& \text { اللّذان كتبا باللغة العربية. } \\
& \text { العلوم العربية هي العلوم التى يتوصل بها } \\
& \text { المرء إلى عُصمة اللسان والقلم عن الخطاء. وهي } \\
& \text { ثلاثة عشر علما: الصرف، والإعراب (ويجمعها } \\
& \text { إسم النّحو)، والرّسم (هو العلم بأصول كتابة } \\
& \text { الكلمات)، والمعانى، والبيان، والبديع، والعروض، } \\
& \text { 1 شيخ المصطفى الغلايين، جامع الدروس العربية الجزء الأول، } \\
& \text { منشورات المكتبة العصرية، بيروت، السنة: } 1993 \\
& 2 \text { K.H. Moch. Anwar, Ilmu Nahwu: } \\
& \text { Terjemahan Matan Al-Jurumiyah dan Imrity, Bandung: } \\
& \text { وتاريخ الأدب، ومتن اللغة. } \\
& \text { إحدى من مباحث العلوم العربية هو } \\
& \text { "الفعل"، هذا العلم مهمّ جدّا عندنا باعتبار أنه مئه } \\
& \text { داخل في ثلاثة عناصر أساسية في دراسة اللغة } \\
& \text { العربية وهي الفعل والاسم والحرف. } \\
& \text { يكون القرآن بالّلغة العربية البلاغية، } \\
& \text { ولأجل معرفته تمام المعرفة فلابدّ من سيطرة العلوم } \\
& \text { الوافية تمكنه من الوصول إلى هدف معاني القرآن } \\
& \text { ضبطا ودقيقا. } \\
& \text { هناك بعض الأخطاء لدى الطلاب } \\
& \text { الجامعي في فهم الآية القرآنية خصوصا ما يتعلق } \\
& \text { بالآية فيها "الفعل"، مثلا في آية "والسلام عليّ } \\
& \text { يوم ولدت ويوم أموت ويوم أبعث حيا (23) } \\
& \text { ذلك عيسى ابن ميمم قول الحقّ الني فيه يمترون } \\
& \text { (24)، أكثر الطلاب يعتقدون أن نبي عيسى قد لد } \\
& \text { توفى، هذا بالنظر إلى ترجمة القرآن الكريم باللغة }
\end{aligned}
$$$$
\text { PT Sinar Baru. } 1990 .
$$ 
العربية فحسب، ولكن لو تأملنا تلك الآية فوجد

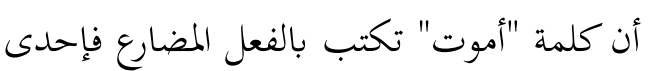
الوظيفة من الفعل المضارع هي دال على الزمن

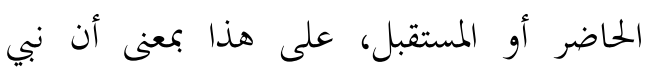
عيسى لم يتوفى.

فبمؤسس على ما سبق ذكره فدراسة

عن اللغة العربية تكون مهمّة عندنا، لذلك أراد الباحث أن يقدم قليلا ما يتعلق بدراسة اللغة

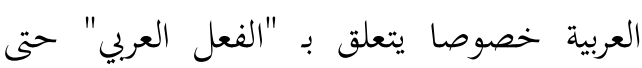

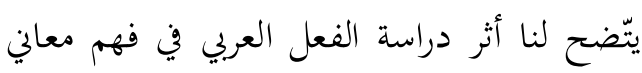

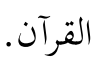

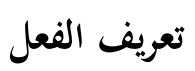

الفعل عند احمد بن عُمَّمَ الحملاوى هو

وضع ليدل على معنى غير مستقل بالفهم، والزمان جزء منه، مثل: كتب، يقرأ وافظ. ${ }^{3}$ وعند مصطفى غلاييني الفعل هو ما دلّ على معنى في نفسه مقترن بزمان كجاء ويجيء وجيء. وعلامته أن يقبل "قد" أو "السين" أو "سوف" أو "تاء التأنيث الساكنة" أو "ضمير الفاعل" أو "نون التوكيد" مثل: قد قام، قد يقوم، ستذهب، سوف نذهب، قامت، قمت، قمتِ، ليكتبنّ،

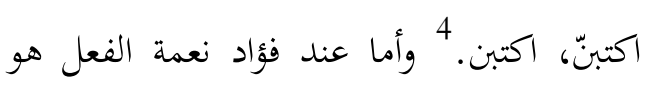
كل كلمة تدل على حدوث شيئ في زمن

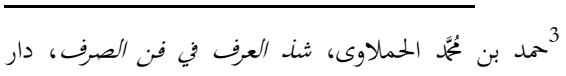

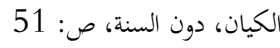

4 المرجع السابق، مصطفى غلاييني، ص: 11-12 د1
}

خاص. 5 وينقسم الفعل إلى ثلاثة وهي ماض ومضارع وأمر. إن الفعل العربي لا بفصح عن الزمان بصيغته وحدها، بل يتحصّل الزمن من بناء الجملة وسياقها؛ فقد تشتمل الجملة على زيادات تعين الفعل على تقرير الزمن في حدود واضحة. 6 غير إن نحاة آخرين كانوا قد تكلموا عن انصراف الماضي عن (الزمن الماضي) إلى الحسال والمستقبل. 7 فالثعلبي، وابن يعيش، قالا بإمكان استعمال الماضي مكان المضارع والمضارع مكان الماضي.

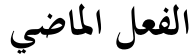
الفعل الماضي هو ما دل على حدوث شيء قلب زمن التكلم. 9 وعند مصطفى غلاييني الفعل الماضي هو ما دل على معنى في نفسه مقترن بالزمان الماضي. 10 وقال الزخشري الفعل الماضي هو الدال على اقتران حدث بزمان قبل زمانك، وقال ابن الحاجب الفعل الماضي هو ما دل على زمان قبل زمانك. ومما يلاحظ في

$$
\begin{aligned}
& 5 \text { فؤاد نعمة، ملخص قواعد اللغة العربية، دار الثقافة }
\end{aligned}
$$

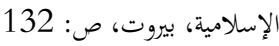

$$
\begin{aligned}
& \text { 6 أممد مجتبى السيد مُحَّة، مغهوم الزمن النحوي ودلالته بين }
\end{aligned}
$$

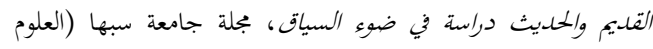

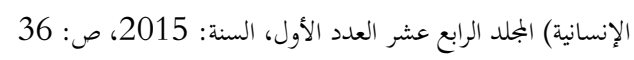

$$
\begin{aligned}
& \text { 7 المصدر نفسه، ص: } 4
\end{aligned}
$$

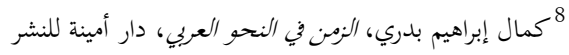

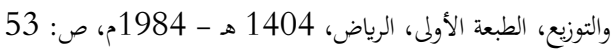

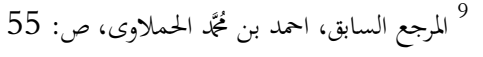

$$
\begin{aligned}
& 10 \text { المرجع السابق، مصطفى غلاييني، ص: } 33
\end{aligned}
$$


تعريفات هؤلاء النحاة إن الماضي زمن واحد لا

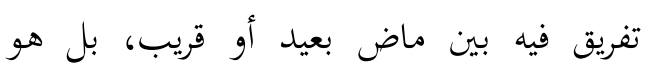
حدث وقع في زمن قبل زمانك، أو هو ما يصح 11 الإخبار عنه في زمان بعد زمان وجوده. أحد من الوزن للفعل الماضي: هي

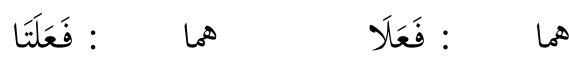

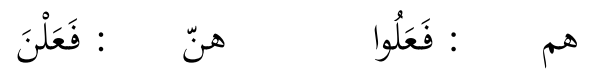

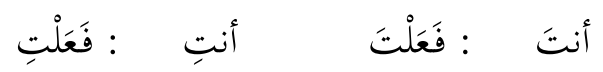

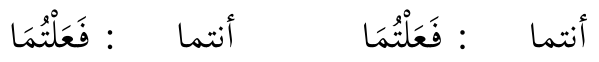

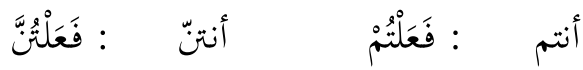

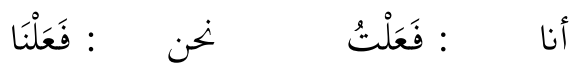
وأحيانا قد تخرج الفعل الماضي عن معناه الحقيقي، وهذا بالنظر إلى سياق الكلام وقرائن الأحوال، منها: 1. دلالة ضيغة الماضي على الزمن الحاضر تدل صيغة الماضي أحيانا على

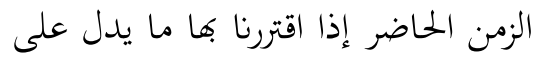
الحاضر؛ وجود قرينة لفظية أو معنوية يتوصل من خلالما إلى معرفة زمن الفعل ومن ذلك اقتران ظروف زمنية معنوية مثل: اليوم أو الآن بضيغة الماضي؛ فتحليل إلى الحاضر، 12 نهو قوله تعالى:

الماضي، 11 علاء عبد الدائم، المقالة: الدلات الزمنية لصيغة الفعل https://www.researchgate.net/publication/30

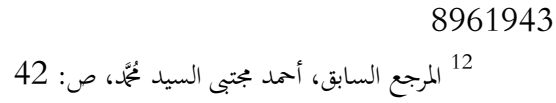

اليوم أكملت لكمم دينكم وأتممت

عليكم نعمتي ورضيت لكم الإسلام

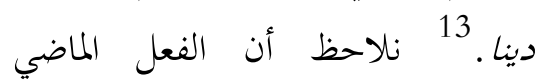
(أكملت) في الآية يدل حسب السياق على الزمن الحاضر بالنسبة لوقت نزول الآية بدليل القرينة اللفظية الظرف الزمني (اليوم)، فقد وردت هذه القرينة اللفظية (اليوم) دالة على ثبوت الحدث وقوعه في الزمن الحاضر. 2. دلالة ضيغة الماضي على المستقبل ترد صيغة الماضي كثير معتبرة عى زمن المستقبل، وذلك فوق سياق النص الذي يتضمنها، وقد أشار إلى هذه الدلالة كثير من الباحثين منهم حامد عبد القادر حيث يقول متحدثا عن اللغة العربية "إن هذه اللغة الحافلة بالعجائب والأسرار نفوق اللغات الحية في استعمال الماضي يحل محل المضارع إذا دل السياق على ذلك. 14 ففي قوله تعالى: يقدم قومه يوم القيامة فأوردهم

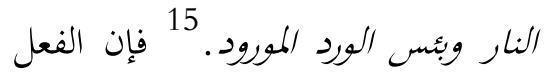
(أوردهم) في الآية يدل بصيغته الصرفية على زمن الماضي غير إنه من خلال السياق يتضح لنا أن الفعل في سياقه

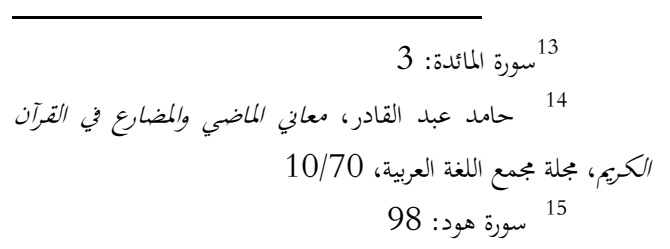


يدل على زمن المستقبل، إذ إن الحلديث يدور حول ما يحدث يوم القيامة، وهذا لئل أمر مستقبلي لم يقع بعد، ونلاحظ أن وقوع صيغة الماضي في سياق استقبلي يخضع لضوابط، وحالات ونكت بلاغية يراد بها تنزيل حوادث المستقبل منزلة حوادث الماضي، وهذا للإشارة إلى أن حدوثها واقع لامحالة مثلها في تحقيق وقوعها في المستقبل. 16

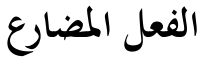

الفعل المضارع عند مصطفى غلاييني هو ما دل على معنى في نفسه مقترن بزمان يحتمل الحال والاستقبال. 17 وعند علي الجارم ومصطفى أمين الفعل المضارع هو كل فعل يدل

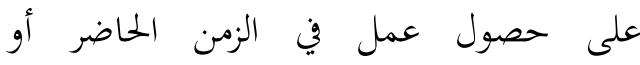

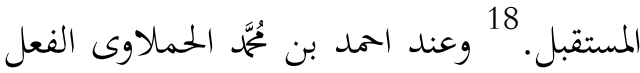
المضارع هو ما دل على حدوث شيئ في زمن التكلم أو بعده. 19

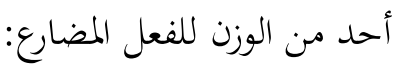

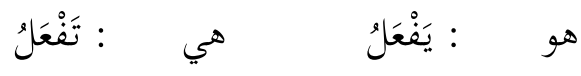

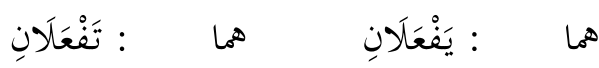

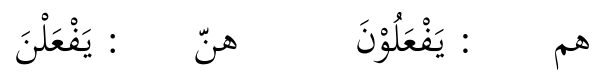

\footnotetext{
16 المرجع السابق، أحمد بجتى السيد يُمَّ، ص: 42

17 1المرجع السابق، مصطفى غلايبني، ص: 33

18 علي الجارم ومصطفى أمين، النحو الواضح الجزيء الأول، دار المعارف، القاهرة، ص: 22

19 المرجع السابق، احمد بن مُحمّة الحملاوى، ص: 56
}

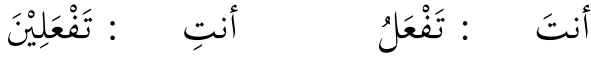

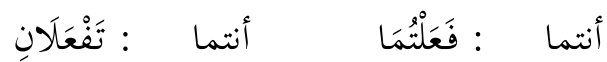

أنتم : تَفْعَلْوَنَ

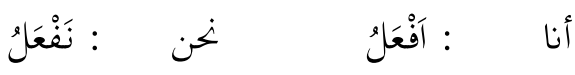
وأحيانا قد تخرج الفعل المضارع عن معناه الحقيقي، وهذا بالنظر إلى سياق الكلام وقرائن الأحوال، وهو يعني: دلالة صيغة المضارع على الزمن الماضي. أشار سيبويه في كتابه إلى وقوع صيغة مكان أخرى في التعابير الزمنية، فيرى أن صيغة المضارع (يفعل) قد تقع في الكلام أحيانا دالة على الزمن الماضي. 20 وتدل صيغة المضارع على الزمن الماضي إذا وردت في جملة حالية مسبوقة بجملة رئيسة فعلها ماض، كقوله

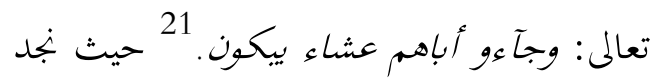
أن الفعل (يبكون) هو فعل مضارع يمثل جملة حالية مسبوقة بجملة رئيسية فعلها ماض (جاء)، فالدلالة الزمنية للفعل المضارع في هذه الحالة هي الدلالة على الماضي حسب سياق القصة.

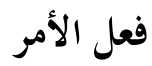
فعل الأمر هو ما دل على طلب وقوع الفعل من الفاعل المخاطب بغير لام الأمر. 22

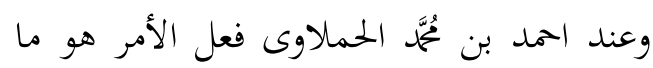
يطلب به حصول شيئ بعد زمن التكلم. 23 وعند

$$
\begin{aligned}
& 20 \text { 20 لمرجع السابق، أحمد بحتبى السيد مُّمَ، ص: } 43 \\
& 21 \\
& 222
\end{aligned}
$$

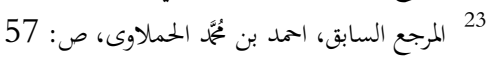


علي الجارم ومصطفى أمين فعل الأمر هو كل فعل يطلب به حصول شيئ في الزمن إنا المستقبل. أحد من الوزن للفعل المضارع: أنعا:

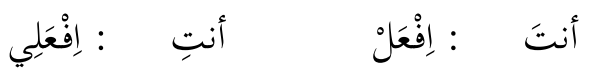

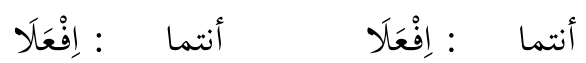

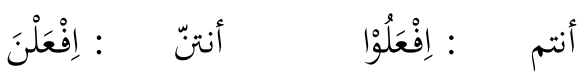
وأحيانا قد تخزج فعل الأمر عن معناه الحقيقي، وهذا بالنظر إلى سياق الكلام وقرائن الأحوال، منها: 1. الدعاء، كقوله تعالى: "رب أوزعنى أن الن

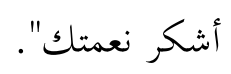

2. الإرشاد، كقوله تعالى: "إذا تداينتم بدين إلى أجل مسمى فاكتبوه وليكتب بينكم الرتافي

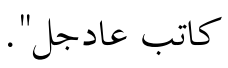

3. التهديد، كقوله تعالى: "اعملوا ما شئتم، إنه بما تعملون بصير".

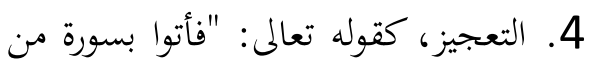
مثله إن كنتم صادقون". 5. الاباحة، كقوله تعالى: "وكلوا واشربوا حتى يتبين لكم الخيط الأبيض من لهن الخيط الأسود من الفجر".

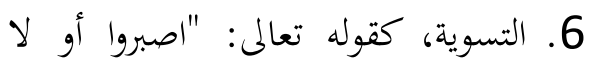

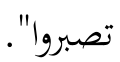

24

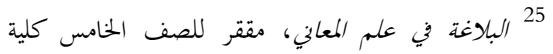

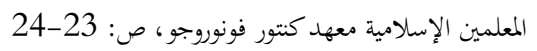

7. الاكرام، كقوله تعالى: "ادخلوها بسلام

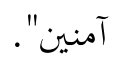

8. الامتنان، كقوله تعالى: "فكلوا مما رزقكم

الله".

9. الاهانة، كقوله تعالى: "كونوا حجارة أو

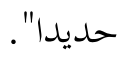

10. الدوام، كقوله تعالى: "اهدنا الصراط

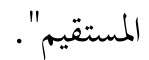

11. الاعتبار، كقوله تعالى: "انر إلى ثمره إذا

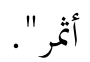

12. التعجب، كقوله تعالى: "انظر كيف

$$
\text { ضربوا لك الأمثال". }
$$

أهمية دراسة عن الفعل العربي في فهم معالي القرآن - - الن

هناك بعض الأخطأ الشائة التي وقعت الت عند الطلاب بجامعة السلطان عبد الرممن الإسلامية الحكومية كفولوان رياو في فهم الآيات

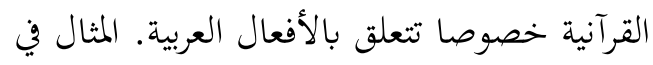
فهم الآية "والسلام عليّ يوم ولدت ويوم أموت

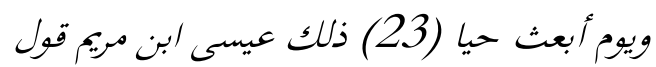

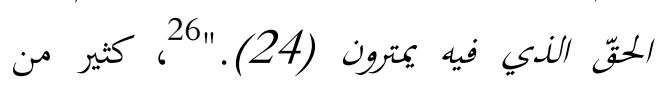

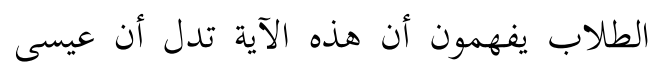
بن مريم قد توف هذا بالنظر إلى ترجمة القرآن الكريع باللغة الإندونيسيا وهي:

Perada: Jurnal Studi Islam Kawasan Melayu, Vol. 2, No. 2, Desember 2019 
"Dan Kesejabteraan semoga dilimpabkan kepadaKu, pada hari aku dilabirkan, pada hari aku meninggal dan pada hari aku dibangkitkan hidup kembali".

"Itulab Isa putera Maryam, yang mengatakan Perkataan yang benar, yang mereka berbantah-bantahan tentang kebenarannya".

ولكن إذا لاحظنا كلمة (أموت)،

لوجدنا أها كتبت بالفعل المضارع، بمعنى أن عيسى بن مريم لم يتوفى، لأن الفعل المضارع تدل على حدوث فعل في الزمن الحاضر أو المستقبل. إذن فهم دراسة الأفعال العربية له دور مهم في

$$
\text { فهم الآيات القرآنية. }
$$

ومثال آخر يعنى في قوله تعالى "اليوم

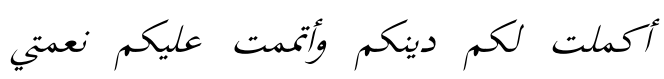

ورضيت لكم الإسلام دينا"، كثير من الطلاب

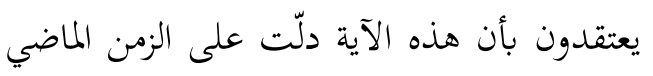
فحسب، هذا بالنظر إلى تعريف الفعل الماضي الذي يقول أنه كل الفعل دل على حدوث في الزمن الماضي. ولكن إذا لاحظنا الآية هناك كلمة "اليوم" هذه الكلمة تكون دليل القرينة اللفطية الظرف الزمني الحاضر، فقد وردت هذه القرينة اللفظية "اليوم" دالة على ثبوت الحدث ووقوعه

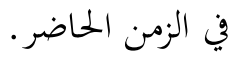
ومثال آخر يعنى في قوله تعالى "رب أوزعني أن أشكر نعمتك" ، لو لاحظنا هذه الآية كأننا نأمر الله عز وجلّا لوجود فعل الأمر فيها، ولكن إذا تعلمنا علم الذي تتعلق بفعل الأمر لوجدنا أن هناك العلم يبين عن فعل الأمر الذي
يخرج من معناه الحقيقي أحدها بمعنى "الدعاء"، إذن من هنا عرفنا أن فعل الأمر في الآية ليس

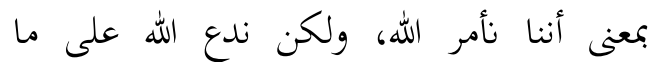
حاجتنا. فبمؤسس على الموقعات الموجودة، فمن الواجب على كل المسلم والمسلمة أن يتعلم دراسة اللغة العربية. لأهميتها الغالية في فهم الآيات القرآنية، باعتبار أها المصدر الأول في الإسلام.

الخايتة

الموضوع (الفكرة) عن دراسة اللغة

العربية يجذبنا على دراستها. بنسبة أفا اللغة الاتصالة المركبة، بل أها لغة الوحي للمسلمين، بحيث مصدران الإسلام وهما القرآن والحديث كتبا باللغة العربية، لذلك لفم القرآن والحديث لابد أن يفهم قواعد اللغة العربية، أحدها وهو "الفعل" وهذا "الفعل" عنصر مهمّ من عناصر اللغة العربية المهمّة جانب "الاسم" و"الحرف". بفهم عن "الفعل العربي" يسهلنا على فهم آيات الهية حتى وصلت الآيات إلى قلوبنا صحيحا

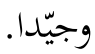
من نتيجة البحث الذي قام به الباحث

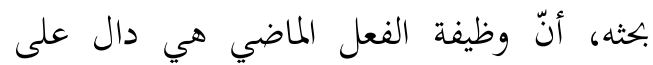
حدوث عمل في الزمان الماضي، ثم وظيفة الفعل المضارع هي دال على حدوث عمل في الزمان الحاضر أو المستقبل، أما وظيفة فعل الأمر هي دال على طلب وقوع الفعل من الأعلى إلى 
الأدنى. ولكن أحيانا قد تخرج الفعل الماضي

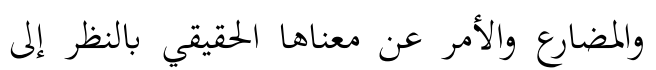
سياق الكلام وقرائن الأحوال. وهذا الحروج المعنوي قدرنا على معرفته بدراسة عميقة عن اللغة العربية خصوصا عن "الفعل"، بتلك لك الدراسة فعرفنا معرفة تامة معاني آية القرآن التي فيها "الفعل" · محا سبق ذكره يستدل لنا أن لمعرفة معاني آية القرآن معرفة تامة لا يكفي بقدرة على تكلم اللغة العربية فحسب، ولاسيما باستدلال على ترجمة القرآن فحسب، إنما تحتاج إلى دراسة عميقة عن كل ما يتعلق بدراسة اللغة العربية منها البلاغة، والنحو، والصرف وغيرها. فلهذا اقترح الباحث للباحثين الآخرين أن يبحثوا الجانب الآخر من هذه الدراسة المتنوعة حتى قدرنا على [ـهم معاني آية القرآن فهما تامّا.

$$
\text { المراجع }
$$

القرآن الكريتم

ترجمة القرآن الكريم في اللغة الإندونيسيا الإمام أبى القاسم جار الله محمود بن عمر بن تُحَّم الزخشرى، تضسير الكشاف الجزء الرابع، دار الكتب العلمية، بيروت - لبنان،

1971

$$
\text { احمد بن مُحَّ الحمالاوى، شن العرف في فن }
$$$$
\text { الصرف، دار الكيان، دون السنة }
$$

أحمد مجتى السيد عُمَّم، مغهوم الزمن النحوي

$$
\text { ودلالته بين القلديم والحلديث دراسة في }
$$

أحمد مصطفى المراغي، علوم البلاغة البيان والمعاني والبليع، دار الكتب العلمية، بيروت، 1993 م أحمد مطلوب، فنون بلاغية - البيان - البليع، الطبعة الأولى، دار البحوث العلمية، الكويت، 1395 هـ - 1975 م جلال الدين مُحَّم بن عدر الرحمن بن عمر بن أحمد بن عُمَّ، الإيضاح في علوم البلاغة ، دار الكتب العلمية، بيروت حامد عبد القادر، معاني الماضي والمضارع في القرآن الكريم، بجلة بجمع اللغة العربية،

$$
10 / 70
$$

$$
\begin{aligned}
& \text { علي الجارم ومصطفى أمين، النحو الواضح الجزء } \\
& \text { الأول، دار المعارف، القاهرة } \\
& \text { الغعل الماضي - (اض }
\end{aligned}
$$

شيخ المصطفى الغلايين، جامع اللوروس العببية الجزء الأول، منشورات المكتبة العصرية،

$$
\text { بيروت، السنة: } 1993
$$

ضوء السياق، جلة جامعة سبها (العلوم الإنسانية) المجلد الرابع عشر العدد

$$
\text { الأول، السنة: } 2015
$$

$$
\text { فؤاد نعمة، ملخص قواعل اللغة العربية ، دار }
$$$$
\text { الثقافة الإسلامية، بيروت }
$$

كمال إبراهيم بدري، النون في النحو العربي، دار أمينة للنشر والتوزيع، الطبعة الأولى،

$$
\text { الرياض، } 1404 \text { هـ - 1984م }
$$




$$
\text { البلاغة في علم المعاني، مقرر للصف الخامس }
$$

K.H. Moch.Anwar, Ilmu Nahwu: Terjemahan Matan Al-Jurumiyah dan Imrity, Bandung: PT Sinar Baru. 1990.

https://www.researchgate.net/publicatio $\mathrm{n} / 308961943$ 